\section{Mandibular Protraction Appliance Effects in Class II Malocclusion in Children, Adolescents and YoungAdults}

Luana Farias Pontes ${ }^{1}$, Francisco Ajalmar Maia², Marcio Rodrigues Almeida ${ }^{3}$, Carlos Flores-Mir ${ }^{4}$, David Normando ${ }^{1}$

\author{
'Department of Orthodontics, \\ Dental School, UFPA - Universidade \\ Federal do Pará, Belém, PA, Brazil \\ ${ }^{2}$ Department of Orthodontics, \\ UFRN - Universidade Federal do Rio \\ Grande do Norte, Natal, RN, Brazil \\ ${ }^{3}$ Department of Orthodontics, \\ UNOPAR - Universidade Norte \\ do Paraná, Londrina, PR, Brazil \\ ${ }^{4}$ Department of Dentistry, University \\ of Alberta, Edmonton, AB, Canada
}

Correspondence: David Normando, Rua Augusto Corrêa, n. 1, 66075110 Belém, PA, Brasil. E-mail: davidnormando@hotmail.com

Key Words: Class II malocclusion, functional appliance, dentofacial development.
The aim of this study was to evaluate the effects of the mandibular protraction appliance (MPA) for treating mild to moderate Class II malocclusion at different stages of dentofacial development. Lateral radiographs were evaluated before (T0) and at the end (T1) of orthodontic treatment with fixed appliance associated with MPA. Sixty-five consecutively treated patients were divided according to the stage of dentofacial development: 21 children in late mixed dentition, 22 adolescents and 22 young adults with full permanent dentition. The differences between and within groups were analyzed by MANOVA at $p<0.05$. The correction of anteroposterior discrepancy (Wits) was significantly reduced in all development stages $(p<0.01)$, with no difference between groups. Class II was corrected predominantly by dental changes in the mandibular arch, with accentuated proclination of the mandibular incisors and mesial displacement of mandibular molars. The MPA had no skeletal effects in any of the groups, except for a mild reduction of SNA $(p=0.018)$ and ANB angles $(p<0.0001)$ among the mixed dentition children. With regard to soft-tissue profile, facial convexity decreased significantly in all groups $(p<0.01)$. In conclusion, the MPA associated with fixed appliance corrected the Class II occlusion, basically by a mandibular arch protrusion. A mild skeletal maxillary change was significant only when this treatment protocol began during mixed dentition.

\section{Introduction}

The ideal treatment for Class II malocclusions in the presence of a mild skeletal discrepancy is the modification of facial growth direction, which could be achieved by the restriction of maxillary growth and/or mandibular reposition. Orthodontic treatment of mandibular retrognathism in children and adolescents is usually made by mandibular propulsors. The growth spurt is the ideal time for this treatment type (1), but there are reports on the use of mandibular propulsor devices in adult patients for compensatory treatment or orthopedic response.

There are several devices developed aiming to treat Class II malocclusions caused by mandibular retrognathism (24). These appliances are divided into removable functional appliances, such as Fränkel regulator, Bionator and the Twin-block, and fixed appliances, including Herbst, Forsus, Twin-force, Xbow and the mandibular protraction appliance (MPA).

There is wide variation in response to treatment with these appliances. One of the aspects contributing to the variation in therapy response to removable appliances is the cooperation of the patient (5). Thus, in recent years, there was preference to use fixed functional appliances, since they have a lower dependence on collaboration and better predictability (6). Furthermore, patient's stage of growth was reported as the major source of variability in skeletal responses to treatment (1).

MPA is a mandibular propulsor that involves simple manufacturing requirements, low cost and easy installation, with no need for special bands or crowns. The device can be built and customized by the orthodontists themselves and should be used together with the fixed appliances. It can be used bilaterally, unilaterally or with differential activation, the last two for the correction of asymmetrical relations of Class II molar and midline deviations (4). The MPA, apart from routine use in patients during pubertal growth curve, is used for children in early stages of dentofacial development and for young adults (4).

The skeletal effects of functional appliances are usually an increase in mandibular growth and sagittal maxillary growth restriction; however, the most significant modifications are dentoalveolar, like distalization of maxillary molars, mesial displacement of mandibular molar, lingual inclination of the maxillary incisors, and labial inclination of mandibular incisors $(2,3)$.

Despite MPA's widespread use in South America, there are only a few reports on its effects $(5,8,9)$ at different 
stages of dentofacial development. Furthermore, these reports do not identify changes caused by MPA according to dentofacial development, an important variable associated with craniofacial changes produced by orthopedic appliances (1). Thus, the objective of this study was to evaluate the dental, skeletal and soft-tissue effects of MPA in the treatment of mild to moderate Class II malocclusion patients at different stages of dentofacial development.

\section{Material and Methods}

The project was approved by the Ethics Committee on Research in Human Beings of the Centro de Ciências da Saúde (CCS/UFPA), under protocol number 442.095 .

Patients with mild to moderate skeletal Class II were treated consecutively in three stages of dentofacial development by two orthodontists with over 20 years of experience. All were treated without extractions and presented at T0, at least a half cusp Class II relationship of canines and molars on both sides. The patient selection criteria for treatment were basically clinical, but included dental cast and skeletal cephalometric records. As a routine, the orthodontists indicated orthognathic surgery only for Class II cases with severe sagittal and/or vertical $\vec{s}$ deformities. Therefore, only cases of mild-to-moderate skeletal discrepancies were included (Fig. 1) treated with MPA associated to pre-adjusted brackets, 0.018 "x0.030 slot, Andrews prescription (Dentaurum, Ispringen, Germany). Retreatment cases, surgical patients, or with implant or prosthetic rehabilitation and syndromic individuals were previously excluded.

The sample size was calculated using Wits analysis as the primary variable. To detect $2 \mathrm{~mm}$ of difference, with an $80 \%$ power and an $\alpha$ level of 0.05 , each group required 23 patients. After collecting data, 65 consecutively treated patients were retrospectively selected, which resulted in a final power of $78 \%$.

The first group consisted of 21 children with mixed dentition (MD), with an initial mean age of 10.1 years $(S D=1.6)$ at T0. Only one patient started and finished the treatment in the mixed dentition group. The remaining patients $(n=20)$ finished their orthodontic treatment in permanent dentition. Thus, all patients, except one, used the MPA associated with a $2 \times 4$ mechanics in the first phase and followed by a full-fixed appliance in the permanent dentition. The second group consisted of 22 adolescents in permanent dentition (PD), with an initial mean age of 13.4 years, while the third group consisted of 22 adult patients (AD), with an initial minimum age (T0) of 18 years and a mean of 26.5 (Table 1).

The frequency of the patient's orthodontic appointments and the duration of treatment were evaluated in months, from installation of the fixed appliance (T0) to the end of the case (T1) (Table 1).

Dental casts the lateral radiographs were analyzed before the start (T0) and at the end of treatment (T1). The initial and final radiographs were obtained using the Instrumentarium 0C200 (Instrumentarium Imaging, Milwaukee, WI, USA) equipment. The rule of cephalostat on all images was measured at a distance of $20 \mathrm{~mm}$, with a Masel Dental Dial Caliper (Masel, Bristol, PA, USA) for image magnification corrections. All radiographs were manually traced by one of the authors on ultraphan paper and scanned using an HP Scanjet G4050 scanner (HewlettPackard Development Company, Palo Alto, CA, USA).

The cephalometric analysis comprised 12 linear and 7 angular measurements. Radiocef 2 software (Radio

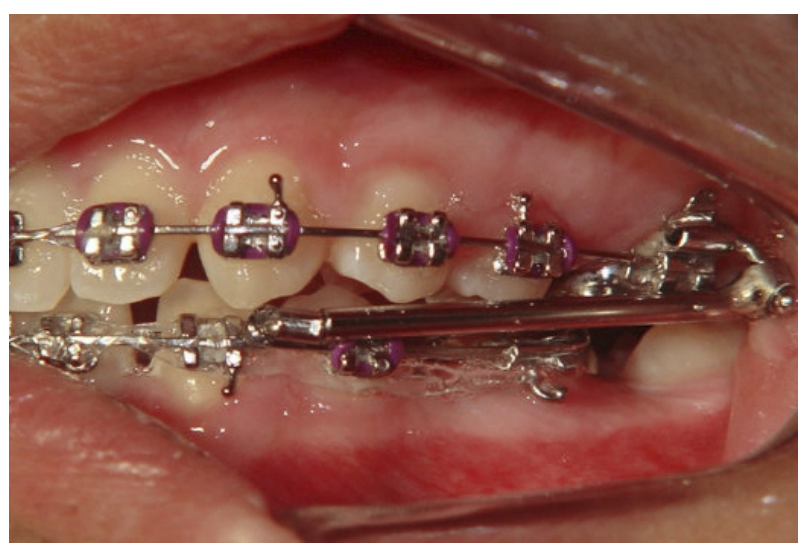

Figure 1. MPA-IV used to produce the mandibular advancement in a patient in permanent dentition.

Table 1. Sample size by sex, mean and standard deviation of the initial and final ages (in years) of the MPA time of use (in months), the number of appointments and treatment time (in months) in the groups of mixed dentition groups, adolescents and adults in permanent dentition

\begin{tabular}{lcccccccc}
\hline Groups & $\mathrm{n}$ & Female & Male & $\begin{array}{c}\text { Age (T0) } \\
\text { Mean (SD) }\end{array}$ & $\begin{array}{c}\text { Age (T1) } \\
\text { Mean (SD) }\end{array}$ & $\begin{array}{c}\text { MPA use } \\
\text { Mean (SD) }\end{array}$ & $\begin{array}{c}\text { Appointments } \\
\text { Median (IQR) }\end{array}$ & $\begin{array}{c}\text { Tx time (years) } \\
\text { Median (IQR) }\end{array}$ \\
\hline $\begin{array}{l}\text { Mixed dentition } \\
\begin{array}{l}\text { Permanent dentition } \\
\text {-Adolescents }\end{array}\end{array}$ & 21 & 10 & 11 & $10.1(1.6)$ & $14.7(1.9)$ & $9.5(4.2)$ & $42(11)$ & $4.1(0.8)$ \\
$\begin{array}{l}\text { Permanent dentition } \\
- \text {-Adults }\end{array}$ & 22 & 11 & 11 & $13.4(2.11)$ & $16.8(2.0)$ & $8.9(4.11)$ & $32.5(14)$ & $3.2(1.5)$ \\
\hline
\end{tabular}


Memory, Belo Horizonte, MG, Brazil) was used to obtain the measurements. The amount of change per year of each patient was calculated by the difference of each variable between $\mathrm{T} 1$ and $\mathrm{T} 0$ divided by the treatment duration in months.

For the analysis of the method error, 15 radiographs were traced twice and measured with a 30-day interval. The Dahlberg formula was used for random error analysis, while intraclass correlation (ICC) was used for the evaluation of systematic errors. Data normality was examined using the Shapiro-Wilk test. A descriptive analysis of data was made and a multiple analysis of variance (MANOVA) was used to evaluate repeated-measures data between $\mathrm{T} 0$ and $\mathrm{T} 1$ in each group. Intergroup comparison of annual changes was

Table 2. Random error (Dahlberg's formulae) and systematic error (intraclass correlation) of cephalometric variables

\begin{tabular}{|c|c|c|}
\hline Variable & $\begin{array}{l}\text { Random } \\
\text { error }\end{array}$ & Systematic error \\
\hline \multicolumn{3}{|c|}{ Maxillomandibular } \\
\hline Wits & 1.05 & 0.69 \\
\hline ANB & 0.31 & 0.95 \\
\hline \multicolumn{3}{|l|}{ Maxilla } \\
\hline A-NPerp & 0.44 & 0.65 \\
\hline SNA & 0.66 & 0.97 \\
\hline Co-A & 2.18 & 0.83 \\
\hline ANS-VertPtmi & 1.27 & 0.91 \\
\hline \multicolumn{3}{|l|}{ Mandible } \\
\hline Pog-Nperp & 0.92 & 0.97 \\
\hline SNB & 0.56 & 0.97 \\
\hline Co-Gn & 1.49 & 0.95 \\
\hline Go-Pog & 0.83 & 0.96 \\
\hline \multicolumn{3}{|c|}{ Vertical relationship } \\
\hline SN-Go.GN & 1.14 & 0.94 \\
\hline ANS-Me & 0.33 & 0.99 \\
\hline S-Go & 1.83 & 0.87 \\
\hline \multicolumn{3}{|l|}{ Teeth } \\
\hline 1.PP & 1.5 & 0.95 \\
\hline IMPA & 1.16 & 0.96 \\
\hline U6-OLP & 0.75 & 0.96 \\
\hline L6-OLP & 0.65 & 0.98 \\
\hline \multicolumn{3}{|l|}{ Soft tissue } \\
\hline H-Nose & 0.77 & 0.74 \\
\hline H Line & 0.84 & 0.93 \\
\hline
\end{tabular}

performed using multiple analyses of variance (MANOVA), with Tukey's post-hoc test. To investigate whether there was any interaction between the two independent variables, stage of dentition and sex of individuals were assessed as factors. All statistical analyses were performed using IBM SPSS Statistics 22 (SPSS Inc., Chicago, IL, USA) software, with a 0.05 level of significance.

\section{Results}

The random error ranged from 0.31 to $2.18 \mathrm{~mm}$ (Table 2). The systematic error analysis presented ICC values between 0.65 and 0.99 , showing a reproducibility of measurements, varying from good to excellent.

Among the patients in mixed dentition and adolescents in permanent dentition, the interaction between dentition stage and sex was not significant ( $p>0.05$ ) as evaluated by repeated-measures MANOVA. The group of adult patients had a different number of female $(n=17)$ and male patients $(n=5)$ and showed no significant interaction between dentition stage and sex for all investigated variables, except for Co-A ( $p=0.023)$.

In the mixed dentition (MD) group, the mean time of MPA use was 9.5 months ( $S D=4.2)$, with a median number of clinical appointments of $42(\mathrm{IQR}=11)$. The median duration of treatment was 4.1 years $(I Q R=0.8)$. In the permanent dentition group (PD), the mean time of MPA use was 8.9 months ( $\mathrm{SD}=4.1)$, with a median number of clinical visits for orthodontic treatment of $32.5(\mathrm{IQR}=14)$, within 3.2 years of treatment time $(I Q R=1.5)$. For the adult subjects $(A D)$, the mean time of MPA use was 8.8 months $(S D=4.3)$, with a median number of clinical visits of $32(I Q R=16.4)$ and median treatment duration of 2.79 years $(\mathrm{IQR}=1.51)$ (Table 1).

Wits appraisal had a significant reduction of $2.59 \mathrm{~mm}$ ( $p<0.05$, Table 3) from T0 $(4.8 \mathrm{~mm})$ to T1 $(1.49 \mathrm{~mm})$ in the MD group. ANB angle showed a small but significant decrease of $1.67^{\circ}(p<0.05$, Table 3$)$. The change in ANB was a result of a minor restriction on the anteroposterior maxillary growth, shown by a decrease of approximately $1^{\circ}$ for the SNA angle ( $p=0.02)$. Class II malocclusion treatment, when started in mixed dentition, was mainly corrected by dentoalveolar changes, primarily via a lower incisor proclination (IMPA) of $3.12^{\circ}$ from T0 to T1 $(p=0.03)$. There was a marked mesial displacement of mandibular molars (L6-OLP), with a mean of $8.92 \mathrm{~mm}(\mathrm{p}<0.05$, Table 3$)$. There was no significant change in the inclination of the maxillary incisors ( $p=0.638$, Table 3 ). However, there was an anterior displacement of the maxillary molars of $5.77 \mathrm{~mm}(p<0.05)$ in relation to sella (U6-OLP)

There was a significant Wits decrease of $3.13 \mathrm{~mm}$ for the permanent dentition group $(p<0.0001)$. However, no significant change was observed in the AP displacement 
of the apical bases (SNA and SNB, $p>0.05$ ). Significant increases of $0.81 \mathrm{~mm}(p<0.017)$ for the maxillary (Co-A) length and $2.04 \mathrm{~mm}(\mathrm{p}<0.05)$ for the mandibular length (Co-Gn) was observed in adolescents (Table 4). However, such changes were not significant in young adult patients ( $p>0.05$, Table 5 ).

The mean labial inclination increase of the lower incisors (IMPA) during treatment was $7.24^{\circ}(p<0.05$; Table 4$)$ or $2.35^{\circ}$ per year for the permanent dentition group, and $6.27^{\circ}(p=0.001$; Table 5$)$ or $2.24^{\circ}$ per year for the adults (Table 6). There was a significant anterior displacement of the maxillary molars $(p<0.05$, Table 4$)$, while the AP position of the maxillary molars was not modified in the adults ( $p=0.075$, Table 5 ). On the other hand, the mesial movement of the mandibular first molars was significant for both groups $(p<0.05$, Tables 4 and 5$)$.

The direction of facial vertical growth (SNGoGn) did not change significantly during the orthodontic treatment with MPA (Tables 3, 4 and 5), while the lower anterior facial height (ANS-Me) and the posterior facial height (S-Go) showed a significant increase in the children (MD) and adolescents (PD) groups ( $<<0.05$; Tables 3 and 4). No significant change in the lower anterior facial height was observed in adults; however, a small significant increase of $1.13 \mathrm{~mm}(p=0.045)$ was observed for their posterior facial height.

Regarding the soft-tissue profile, the H-Nose values increased significantly for the group in mixed dentition $(5.29 \mathrm{~mm}, \mathrm{p}<0.05)$ and the adolescents $(2.97 \mathrm{~mm}, \mathrm{p}<0.05)$. A slight increase $(0.82 \mathrm{~mm})$ of this measurement was also observed in the adults ( $p=0.009$, Table 5$)$. The facial convexity (H Line) decreased significantly in all groups, although most significantly in the mixed dentition $\left(3.5^{\circ}, p<0.05\right)$ and in the adolescents at permanent dentition $\left(1.58^{\circ}, \mathrm{p}=0.005\right)$.

As to the annual differences that occur during orthodontic treatment (Table 6), there was no significant effect on the interaction between the developmental stage in which the treatment was carried out and sex $(p=0.52)$. Thus, the analysis was pooled for both sex.

Patients in mixed dentition and adolescents in permanent dentition showed no differences in the annual changes in any of the analyzed variables (Table 6). However, in comparison to the group of adults, it was observed that the ANB angle showed a small decrease in patients in mixed dentition ( $p>0.05)$. The linear growth variables representing the vertical (S-Go, ANS-Me) and horizontal growth of the face (Go-Pog Co-Gn, ANS-VertPtmi) showed a significant increase in the mixed dentition subjects and the adolescents compared with the adults (Table 6).

\section{Discussion}

The study findings demonstrated that Class II correction with MPA could be obtained primarily by dental changes by a significant labial displacement of the mandibular arch. The small effect on growth was significant only among children that started treatment in the mixed dentition. However, there was a significant reduction of around $3 \mathrm{~mm}$ in the Wits appraisal 
in all groups. Wits analysis evaluates the anteroposterior maxillomandibular relationship near to the dentoalveolar region, while ANB evaluates this relation considering the cranial base. In order to obtain a more precise diagnosis of the relationship between apical bases, the ANB angle and Wits analysis should be analyzed together (10). Wits analysis was not used in any previous investigation of patients with MPA.

While a significant change was noticed in Wits analysis, the ANB was significantly reduced only in patients who started treatment in mixed dentition $(p<0.05$, Table 3$)$ and finished in permanent dentition. Although there is no

Table 4. Mean, standard deviation (SD) and difference of the means of the variables analyzed in the adolescent group in permanent dentition $(n=22)$ treated with mandibular protraction appliance and MANOVA for repeated measures

\begin{tabular}{|c|c|c|c|c|c|c|}
\hline Variable & $\begin{array}{c}\text { Mean } \\
\text { T0 }\end{array}$ & SD & $\begin{array}{c}\text { Mean } \\
\text { T1 }\end{array}$ & SD & $\begin{array}{l}\text { Difference } \\
\text { of means }\end{array}$ & $\begin{array}{c}\text { MANOVA } \\
\text { p-value }\end{array}$ \\
\hline \multicolumn{7}{|c|}{ Maxillomandibular } \\
\hline Wits & 6.41 & 2.6 & 3.28 & 2.9 & -3.13 & $<0.0001^{* * * *}$ \\
\hline ANB & 5.37 & 1.3 & 4.81 & 1.5 & -0.56 & 0.075 \\
\hline \multicolumn{7}{|l|}{ Maxilla } \\
\hline A-NPerp & 0.43 & 2.9 & -0.12 & 3.6 & -0.55 & 0.25 \\
\hline SNA & 83.03 & 3.1 & 82.57 & 3.6 & -0.46 & 0.34 \\
\hline Co-A & 94.16 & 4.9 & 97.26 & 3.6 & 3.1 & $0.002^{* * * *}$ \\
\hline ENA-VertPtmi & 58.48 & 3.2 & 61.19 & 4.1 & 2.71 & $<0.0001^{* * *}$ \\
\hline \multicolumn{7}{|l|}{ Mandible } \\
\hline Pog-Nperp & -8.43 & 5.2 & -8.25 & 5.3 & 0.18 & 0.76 \\
\hline SNB & 77.69 & 2.9 & 77.82 & 2.6 & 0.13 & 0.63 \\
\hline Co-Gn & 119 & 7.4 & 125.7 & 5.4 & 6.75 & $<0.0001^{* * * *}$ \\
\hline Go-Pog & 81.9 & 6.2 & 85.43 & 5 & 3.53 & $<0.0001^{* * * *}$ \\
\hline \multicolumn{7}{|c|}{ Vertical relationship } \\
\hline SN-Go.GN & 34.07 & 3.5 & 34.16 & 4.4 & 0.09 & 0.82 \\
\hline ENA-Me & 71.56 & 5.3 & 76.81 & 5.9 & 5.25 & $<0.0001^{* * * *}$ \\
\hline S-Go & 77.49 & 5 & 82.43 & 5.1 & 4.94 & $<0.0001^{* * * *}$ \\
\hline \multicolumn{7}{|l|}{ Teeth } \\
\hline 1.PP & 111.6 & 7.2 & 113.1 & 4.5 & 1.45 & 0.36 \\
\hline IMPA & 95.76 & 5.3 & 103 & 5.6 & 7.24 & $<0.0001^{* * * *}$ \\
\hline U6-OLP & 60.23 & 5.1 & 63.03 & 4.9 & 2.8 & $<0.0001^{* * * *}$ \\
\hline L6-OLP & 60.43 & 5.3 & 65.04 & 5.1 & 4.61 & $<0.0001^{* * * *}$ \\
\hline \multicolumn{7}{|l|}{ Soft tissue } \\
\hline H-Nose & 0.94 & 3.6 & 3.91 & 3.3 & 2.97 & $<0.0001^{* * *}$ \\
\hline H Line & 15.22 & 3.7 & 13.64 & 3.8 & -1.58 & $0.005^{* * * *}$ \\
\hline
\end{tabular}

${ }^{*} \mathrm{p}<0.05 ;{ }^{* *} \mathrm{p}<0.01 ;{ }^{* * *} \mathrm{p}<0.001$ other study in the literature regarding the specific effect of MPA in mixed dentition children, a previous study showed that MPA (5) is unable to restrain the anterior maxillary growth in a sample of pooled patients from mixed and permanent dentition. In the present study, the restrictive anteroposterior effect over maxillary growth was not observed in patients in the permanent dentition, adolescents or adults, suggesting that the patient's dentofacial stage possibly affects the maxillary skeletal changes when this appliance is used.

Regarding skeletal changes produced by Class II correctors, a systematic review showed that the most important factor is not the type of functional appliance but the growth stage when it is applied (1). In the present study, the anterior mandible growth (SNB) did not change significantly in any of the studied groups. Previous studies, however, reported a significant effect of MPA of mandibular growth in adolescents (7), but of smaller magnitude when compared with other functional appliances. Thus, MPA should be avoided in cases that could benefit from a significant increase in mandibular growth at any dentofacial stage.

The total mandibular length ( $\mathrm{Co}-\mathrm{Gn})$ and the mandibular body (Go-Gn) showed a significant increase for the groups in mixed dentition and adolescents during treatment (Tables 3 and 4), while such changes for adults were not significant. These results, despite corroborating data from previous studies $(8,9)$, should not be considered as a skeletal gain produced by MPA, since the growth rates obtained are similar to those reported for Class II untreated subjects for children in mixed (11) or adolescents in permanent dentition (12). For adults, there was a significant interaction between the stage of dentition and the patient's sex for the Co-A variable ( $p=0.023)$ only. However, this result does not seem important in the general context, where the Co-A measurement showed no significant differences between groups (Table 5).

Concerning vertical changes, growth direction (SNGoGn) has not been modified in any of the examined groups, as previously reported $(5,8,11)$. However, vertical linear measurements of the face (S-Go, ANS-ME) increased significantly during the orthodontic treatment in groups of growing patients, mixed and permanent dentition. In adult patients, a slight but significant increase in posterior facial height was observed (S-Go), a finding previously described in the literature (8).

The labial inclination of the mandibular incisors (IMPA) and the mesial displacement of mandibular 
molars (L6-PLO) were observed in all the examined stages of development (Tables 3, 4 and 5). This is a common result reported in previous studies that examined the effect of MPA in adolescents $(5,9)$ or adults (8). However, the protrusive effect of the appliance into the mandibular incisors seems more pronounced in adolescents and adults, around $2.3^{\circ}$ per year, compared with mixed dentition, where this change was $0.85^{\circ}$ per year. The smaller labial inclination of mandibular incisors in the mixed dentition subjects may be associated with the increased skeletal effect of MPA. Conversely, there was no significant change in maxillary incisor inclination (1.PP) in any phase of dentofacial development, suggesting that while the fixed appliance is able to counteract the effects of headgear in the maxillary arch, a labial protrusion in the mandibular arch is necessary to obtain inter-arch compensatory sagittal correction.

Excessive inclination of mandibular incisors might imply in an increased risk to surrounding periodontal health. However, a systematic review (13) showed no association between gingival recession and protrusion of mandibular incisors. The risk of recession seems to related to a thin attached gingiva, a narrow mandibular symphysis, inadequate plaque control and aggressive brushing by the patient. Thus, in addition to cephalometric changes, a detailed analysis of periodontal biotype is required prior to treatment of Class II malocclusion with appliances that generate an accentuated protrusion of the mandibular dental arch (14). Root resorption is another risk factor among patients undergoing mandibular dental protrusion (15) These dental and periodontal changes should be investigated when Class II treatment is applied using MPA appliance.

In addition to changes in the mandibular arch, previous studies have reported that MPA produces a distal movement of the maxillary molars (5). In the present study was found an anterior movement of the maxillary molars relative to the perpendicular line to the occlusal plane drawn from sella (U6-OLP) in patients in younger patients, mixed dentition and adolescents. However, in adult patients, the position of the maxillary molars did not change. The forward displacement of molars, as measured in the present study, is an indistinguishable combination of maxilla anterior displacement and molar movement within the bone base. Thus, the study findings suggest that the distal movement of the maxillary arch is not a marked effect of treatment with MPA, as reported for the twin-block appliance (16). Supporting this assumption, the results obtained in adults showed no significant change.

The soft-tissue analysis with the $\mathrm{H}$-line and $\mathrm{H}-$ Nose showed an improved facial profile convexity in all groups (Tables 3,4 and 5). Although changes in soft tissue occurred more significantly in children and adolescents (Tables 3 and 4), a mild yet significant change was observed in adults (Table 5). The improvement in facial convexity of soft tissue after use of functional appliances for mandibular propulsion was previously reported in the literature for patients in mixed dentition, adolescents and 
adults (17-19). However, relapses may occur (18). in addition to the low predictability of long-term effects of treatment , and the magnitude of these changes may not be clinically perceived $(20,21)$

In conclusion, the study findings showed that the mandibular protraction appliance (MPA) improves Class II malocclusion in different stages of dentofacial development mostly by dental changes by a marked labial displacement of the mandibular arch. In mixed dentition patients, MPA showed a mild restraining effect of sagittal maxillary growth, which was not observed in the adolescent and adult groups. Regarding the facial convexity assessed by softtissue analysis, it had significant improvement at all stages.

Although Class II malocclusion requires a longer treatment in adolescents (22), is the authors believe that, because they do not depend on patient compliance, fixed propulsors could abbreviate treatment duration. The treatment time was $2.79(\mathrm{IQR}=1.51)$ years for adults and $3.2(\mathrm{IQR}=1.5)$ and $4.1(\mathrm{IQR}=0.8)$ years for adolescents and children in mixed dentition, respectively. Treatment time seems shorter than the 48 months of treatment previously reported for adults treated with MPA (8), but greater than the 30 months described for adolescents treated with the Herbst appliance combined to fixed orthodontic appliances (23) or the 32 months from a pooled sample of children and adolescents treated with MPA associated to fixed orthodontic appliance (24). The longest treatment time in patients whose treatment started in the mixed dentition is probably related to a "waiting period" during the transition from mixed to permanent dentition. Furthermore, it is possible that treatment time variability could be catched up related to the final quality of the completion of the orthodontic treatment, which was not investigated in this study.

The retrospective nature of the present investigation, even considering that the cases were selected consecutively, increases the possibility of bias. Another important limitation is the lack of data that could quantify the dental and skeletal changes exclusively by MPA use. The skeletal gains, while using the mandibular propulsor, seem to disperse during the finalization phase with fixed appliances in a "catch-up effect" described in the literature (25)

To quantify the effects of MPA appliance from growth is a complicated task to perform. Patients included in this study made the initial records before the fixed appliance. It is important to emphasize that treatment of around 6 months of alignment is needed before beginning MPA treatment. Respecting ethical 
principles and the Allara protocol, the patients should not be unnecessarily exposed to $x$-rays, turning it unfeasible to carry out new radiographs right before and immediately after the removal of MPA. Although this conduct is not ideal to identify the real effects of MPA only, it is a daily routine in the orthodontic treatment and represents the real life.

The group of adult patients was not matched according to sex, with 17 women and 5 men. At first, it was thought there would be a significant difference when the interaction between dentition stage and sex is assessed, which makes the findings unreliable for this. However, just one variable (Co-A) showed a significant interaction.

Limitation of lack of an untreated control group in this study prevents greater precision in discussing the real effects of the appliance versus the changes inherent to normal craniofacial growth. However, maintaining patients without treatment and exposing them to radiation might be ethically questioned. Furthermore the knowledge of craniofacial growth in untreated Class II patients is widely reported. For a proper evaluation of the results of Class II treatment using MPA, except for the effects of natural facial growth, the treated groups were compared with untreated Class II samples previously published in the $\vec{z}$ literature $(11,12)$.

\section{Resumo}

0 objetivo deste trabalho foi avaliar os efeitos do aparelho de protração mandibular (APM) no tratamento da má oclusão de Classe II com discrepância esqueletal leve a moderada, em diferentes estágios de desenvolvimento dentofacial. As telerradiografias em norma lateral foram avaliadas antes (T0) e após (T1) o tratamento ortodôntico com aparelho fixo associado ao APM. Sessenta e cinco pacientes tratados consecutivamente foram divididos de acordo com o estágio de desenvolvimento dentofacial: 21 crianças na dentição mista, e 22 adolescentes e 22 adultos com dentição permanente completa. As diferenças inter e intra grupos foram analisadas através da MANOVA $(p<0,05)$. A correção da discrepância anteroposterior (Wits) foi significativamente reduzida em todos os estágios de desenvolvimento $(p<0,01)$, sem diferença entre os grupos. A má oclusão de Classe II foi corrigida, predominantemente, por alterações dentárias na arcada inferior, com proclinação acentuada dos incisivos inferiores e deslocamento mesial dos molares inferiores. $0 \mathrm{APM}$ não produziu efeitos esqueléticos em nenhum dos grupos, com exceção de uma redução suave do SNA $(p=0,018)$ e ângulo ANB $(p<0,0001)$ nas crianças em fase de dentadura mista. Em relação aos tecidos moles, a convexidade facial diminuiu significativamente em todos os grupos $(p<0,01)$. Conclui-se que o APM associado ao aparelho fixo corrigiu a má oclusão de Classe II basicamente, através da protrusão dentoalveolar do arco inferior. Apenas quando o tratamento se inicia durante a dentição mista, foi possivel identificar uma suave mudança esquelética na maxila.

\section{References}

1. Cozza P, Baccetti T, Franchi L, De Toffol L, McNamara JA Jr. Mandibular changes produced by functional appliances in Class II malocclusion: a systematic review. Am J Orthod Dentofacial Orthop 2006;129:599.e1-12.

2. Flores-Mir C, Young A, Greiss A, Woynorowski M, Peng J. Lower incisor inclination changes during Xbow treatment according to vertical facial type. Angle Orthod 2010;80:1075-1080.

3. Flores-Mir C, Barnett G, Higgins DW, Heo G, Major PW. Short-term skeletal and dental effects of the Xbow appliance as measured on lateral cephalograms. Am J Orthod Dentofacial Orthop 2009;136:822-832.

4. Coelho Filho, CM. The mandibular protraction appliance IV. R Dental Press Ortodon Ortop Facial 2002;7:49-60.

5. Jena AK, Duggal R. Treatment effects of twin-block and mandibular protraction Appliance-IV in the correction of Class II malocclusion. Angle Orthod 2010;80:485-491.

6. Jena AK, Duggal R. Treatment effects of twin-block and mandibular protraction Appliance-IV in the correction of Class II malocclusion. Angle Orthod 2010;80:485-491.

7. Franchi L, Pavoni C, Faltin K Jr, McNamara JA Jr, Cozza P. Long-term skeletal and dental effects and treatment timing for functional appliances in Class II malocclusion. Angle Orthod 2013;83:334340.

8. Stahl F, Baccetti T, Franchi L, McNamara JA Jr. Longitudinal growth changes in untreated subjects with Class II Division 1 malocclusion. Am J Orthod Dentofacial Orthop 2008;134:125-137.

9. Furquim BD, Henriques JFC, Janson G, Siqueira DF, Furquim LZ. Effects of mandibular protraction appliance associated to fixed appliance in adults. Dental Press J Orthod 2013;18:46-52.

10. Araújo EM, Matoso RM, Diogenes AMN, Lima KC. Cephalometric evaluation of the effects of joint use of a mandibular protraction appliance (MPA) and a fixed orthodontic appliance on the skeletal structures of patients with Angle Class II, division 1 malocclusion. Dental Press J Orthod 2011;16:113-124.

11. Bishara SE, Fahl JA, Peterson LC. Longitudinal changes in the ANB angle and Wits appraisal: clinical implications. Am J Orthod 1983;84:133-139.

12. Almeida MR, Henriques JF, Almeida RR, Almeida-Pedrin RR, Ursi W. Treatment effects produced by the Bionator appliance. Comparison with an untreated Class II sample. Eur J Orthod 2004;26:65-72.

13. Ehsani S, Nebbe B, Normando D, Lagravere MO, Flores-Mir C. Dental and skeletal changes in mild to moderate Class II malocclusions treated by either a Twin-Block or a XBow appliance followed by full fixed orthodontic treatment. Angle Orthod 2015;85:997-1002.

14. Aziz T, Flores-Mir C. A systematic review of the association between appliance-induced labial movement of mandibular incisors and gingival recession. Aust Orthod J 2011;27:33-39.

15. Pancherz $\mathrm{H}$, Bjerklin K. Mandibular incisor inclination, tooth irregularity, and gingival recessions after Herbst therapy: a 32-year follow-up study. Am J Orthod Dentofacial Orthop 2014;146:310318.

16. Tieu LD, Saltaji $H$, Normando D, Flores-Mir C. Radiologically determined orthodontically induced external apical root resorption in incisors after non-surgical orthodontic treatment of Class II division 1 malocclusion: a systematic review. Prog Orthod 2014;23;15:48.

17. Ehsani S, Nebbe B, Normando D, Lagravere MO, Flores-Mir C. Short-term treatment effects produced by the Twin-block appliance: a systematic review and meta-analysis. Eur J Orthod 2015;37:170-176.

18. Landázuri DR, Raveli DB, Santos-Pinto A, Dib LP, Maia S. Changes on facial profile in the mixed dentition, from natural growth and induced by Balters' bionator appliance. Dental Press J Orthod 2013;18:108-115.

19. Pancherz $H$, Anehus-Pancherz M. Facial profile changes during and after Herbst appliance treatment. Eur J Orthod 1994;16:275-286.

20. Bock NC, Santo C, Pancherz H. Facial profile and lip position changes in adult Class II, Division 2 subjects treated with the Herbst-Multibracket appliance. A radiographic cephalometric pilot study. J Orofac Orthop 2009;70:51-62.

21. Flores-Mir C, Major MP, Major PW. Soft tissue changes with fixed functional appliances in Class II division 1. Angle Orthod 2006;76:712-720.

22. Barroso MC, Silva NC, Quintão CC, Normando D. The ability of orthodontists and laypeople to discriminate mandibular stepwise advancements in a Class II retrognathic mandible. Prog Orthod 2012:13:141-147. 
23. Mavreas D, Athanasiou AE. Factors affecting the duration of orthodontic treatment: a systematic review. Eur J Orthod 2008;30:386-395.

24. Alvares JC, Cançado RH, Valarelli FP, Freitas KM, Angheben CZ. Class II malocclusion treatment with the Herbst appliance in patients after the growth peak. Dental Press J Orthod 2013;18:38-45.

25. Siqueira DF, Almeira RR, Janson G, Brandão AG, Coelho Filho CM. Dentoskeletal and soft-tissue changes with cervical headgear and mandibular protraction appliance therapy in the treatment of Class II malocclusions. Am J Orthod Dentofacial Orthop 2007;131:447.e21-30

26. Lai M, McNamara JA Jr. An evaluation of two-phase treatment with the Herbst appliance and preadjusted edgewise therapy. Semin Orthod 1998;4:46-58.

Received August 15, 2016 Accepted February 13, 2017 